\title{
Current knowledge and future challenges in camelid reproduction
}

\author{
A Tibary', A Anouassi ${ }^{2,3}$, A Sghiri ${ }^{2}$ and H Khatir ${ }^{3}$ \\ Department of Veterinary Clinical Sciences and Center for Reproductive Biology, Washington State \\ University, Pullman, WA, USA 99164-6610, '2Department of Reproduction and Artificial Insemination, \\ Institut Agronomique et Vétérinaire Hassan II, B.P. 6202, Rabat-Institut, Moroccco, ${ }^{3}$ Veterinary research \\ Center, Abu Dhabi, United Arab Emirates, PO Box. 44479
}

\begin{abstract}
Reproductive biology research on camelids offers some interesting peculiarities and challenges to scientists and animal production specialists. The objective of this paper is to review camelid reproduction, advances in reproductive physiology and reproductive biotechnologies in camelids and discuss some areas for further research. In the female, the focus has been on understanding follicular dynamics. This has allowed development of synchronization and superovulation strategies to support embryo transfer technologies which are now commonly used in camels. Some advances have been achieved in preservation of embryos by vitrification. Fertilization, early embryo development and embryo signaling for maternal recognition of pregnancy are still not fully understood. New information on the interaction of the developing embryo and the endometrium may shed some light on this signaling as well as the mechanism of prevention of luteolysis. The presence of a seminal ovulation-inducing factor (OIF) was confirmed in llamas and alpacas. Chronology of oocytes maturation has been described. In vitro production of embryos has been achieved resulting in successful pregnancies and births in the dromedary. These techniques offer a new tool for the production and study of interspecies/cross-species embryos and their effect on pregnancy. Male reproductive function remains poorly studied. Semen preservation and artificial insemination still present many challenges and are not used in production at the moment. The involvement of climatic and nutritional conditions as well as the role of leptin in the regulation of reproductive function need to be evaluated.
\end{abstract}

\section{Introduction}

Camelidae are economically important in many countries. There are six species, two old world camelids (OWC); Camelus dromedarius and Camelus bactrianus and four new world camelids (NWC); Lama glama, Lama pacos (renamed Vicugna pacos), Lama guanacoe and Vicugna vicugna. Domestic camelids show a variety of "breeds" with specific production characteristics. Camelid reproductive biology research has seen tremendous development in recent years due to renewal of interest for these species. The application of hormone assays and ultrasonog- 
raphy have permitted great advances in this area (Anouassi et al. 1988; Tibary \& Anouassi 1996). The objective of the present paper is to review camelid reproduction and to point out areas for future research, focusing on reproductive physiology and applied biotechnologies. Recent reviews are available for discussion of reproductive disorders in camelids (Tibary et al. 2005b; Tibary \& Vaughan 2006; Vaughan \& Tibary 2006).

\section{Reproduction in the male camelid}

Reproductive parameters of the male are critical for evaluation of the prospective herd sire and are summarized in Table 1.

Table 1: Reproductive parameters in male camelids (adapted from Tibary \& Anouassi 1997; Bravo 2002; Tibary \& Vaughan 2006)

\begin{tabular}{|c|c|c|c|c|}
\hline Parameter & C. dromedaries & C. bactrianus & L. pacos & L. glama \\
\hline Testicular descent & Present at birth & Present at birth & Present at birth & Present at birth \\
\hline Puberty & 3 to 5 years & 3 to 5 years & 15 to 24 months & 15 to 24 months \\
\hline Sexual maturity (years) & 5 to 6 & 5 & 4 & 4 \\
\hline Seasonality & Yes & Yes & sometimes & sometimes \\
\hline Testicular size at maturity & $36.4 \mathrm{~cm}^{2}$ & 3 & $3.7 \times 2.5^{* *}$ & $5.4 \times 3.3^{* *}$ \\
\hline Duration of Spermatogenesis & ? & ? & $?$ & ? \\
\hline Sperm production per gram of test & is 20 to $61 \times 10^{6}$ & ? & ? & ? \\
\hline Daily sperm production & $0.751 \times 10^{9}$ & ? & $?$ & $?$ \\
\hline Gonadal sperm reserve reserves & $1.7-3.4 \times 10^{7}$ & 3 & ? & ? \\
\hline Epididymal transit & 4.3. days & ? & ? & ? \\
\hline Epididymal sperm reserve & $2.3-6.1 \times 10^{4}$ & ? & ? & ? \\
\hline Mating duration (minutes) & $7-20$ & $3-20$ & $5-50$ & $5-65$ \\
\hline \multicolumn{5}{|l|}{ Ejaculate characteristics } \\
\hline Volume $(\mathrm{ml})$ & $2-13$ & $2.5-12.5$ & 0.4 .4 .3 & $0.2-7.9$ \\
\hline Concentration $\left(\times 10^{6} / \mathrm{ml}\right)$ & $140-1,300$ & $450-5,590$ & $0.06-170$ & $15-640$ \\
\hline Total spermatozoa $\left(\times 10^{6}\right)$ & $600-5,690$ & $?$ & $0.06-167$ & $2.9-246$ \\
\hline Motility (\%) & $20-80$ & $70-90$ & 85 & $50-95$ \\
\hline Normal Morphology (\%) & $40-70$ & $50-90$ & $40-75$ & $40-85$ \\
\hline \multicolumn{5}{|l|}{ Sperm cell dimensions $(\mu \mathrm{m})$} \\
\hline Total length & $51.1 \pm 0.9$ & $42 \pm 1.9$ & $?$ & 49,5 \\
\hline Head length & $6.6 \pm 0.5$ & $6.0 \pm 0.6$ & ? & 5.3 \\
\hline Head width & $3.8 \pm 0.1$ & $3.9 \pm 0.1$ & $?$ & 3.8 \\
\hline Midpiece & $6.8 \pm 0.5$ & $6.2 \pm 0.7$ & ? & 5.3 \\
\hline Tail & $37.6 \pm 0.9$ & $30.8 \pm 1.9$ & $?$ & 36.6 \\
\hline
\end{tabular}

${ }^{*}$ scrotal circumference, ${ }^{* *}$ Length by width

Sexual development and puberty

Anatomy of genital organs has been reviewed extensively (Tibary \& Anouassi 1997; Tibary \& Vaughan 2006). The most notable feature is the absence of seminal vesicles. The testicles are already descended at birth but may not be easily palpable until 6 months of age in OWC.

Male NWC can display sexual activity as early as 11 months of age. Preputial detachment and complete erection and intromission are possible at 15 months but may take up to 3 years. Presence of spermatozoa in the seminiferous tubules was reported at 15-18 months of age in the alpaca. Testicular growth is slow and does not plateau until 3 years of age (Tibary \& Vaughan 
2006). In the vicuna, spermatogenesis is present at 16 months of age. Guanaco and vicuna males live in a bachelor band until they reach maturity between 4 and 6 years of age, at which point they start forming their own harem (Tibary \& Vaughan 2006).

In the OWC, rutting behavior may be seen as early as 2 years of age, but spermatogenesis and fertilization are not possible until 3 years at the earliest. Sexual maturity ( 5 to 6 years) is signaled by the plateau in spermatogeneic activity (AI-Qarawi et al., 2001). Reduction of spermatogenic activity, libido and expression of male behavior are observed after 20 years (Tibary \& Anouassi 1997).

\section{Spermatogenesis, sperm production and sperm maturation}

The cycle of the seminiferous tubule in the male llama and dromedary presents 8 stages (Delhon \& Von Lawzewitsch 1987; Bustos-Obregon et al, 1997). Differences in the frequency of each stage exist between the two species. Epididymal maturation and transit has been estimated to be 4.3 days in the dromedary. Histologically and histochemically different segments were identified in the epididymis in llamas (Delhon \& Von Lawzewitsch 1994) and camels (Tingari \& Moniem 1979).

Testicular weight is correlated with spermatogenesis and epididymal sperm reserves. However, sperm production and gonadal sperm reserves are lower than those of ruminants. Sperm production is affected by age and season (Tibary \& Anouassi 1997; Tibary \& Vaughan 2006).

Seasonality of reproduction in the male OWC and vicuna has been established through endocrinological, behavioral and histological studies (Tibary \& Vaughan 2006). Testicular size decreases in winter in vicunas (Urquieta et al. 1994) and in summer in camels (Tibary \& Anouassi 1997). Sperm production and quality is lower in summer in llamas (Tibary \& Vaughan 2006). The mechanism regulating seasonality in male camelids remains poorly studied.

\section{Mating behavior and ejaculation}

Mating behavior has been extensively described (Tibary \& Anouassi 1997; Tibary \& Vaughan 2006). In OWC, rutting season is evidenced by increase poll gland secretions, exteriorization of the soft palate and increased urine marking behavior. All camelids mate with the female in a sternal recumbency and mating lasts an average of 20 minutes. Duration of copulation in alpacas is affected by the age of females (longer for multiparous) and by the presence of other males (shorter) (Tibary \& Vaughan 2006).

Semen is delivered continuously throughout mating, in non-fractioned small quantities, via a combination of pelvic thrusts and rhythmic urethral pulses throughout copulation (Lichtenwalner et al. 1996; Lichtenwalner et al. 1997; Tibary \& Anouassi 1997). Copulation length affects ovulation induction rate but does not affect conception rates of ovulating females (Table 2). Sperm cells are present in the ejaculate within 2 to 5 minutes of copulation. Semen is deposited partly deep in both uterine horns and partly in the cervix and vagina (Tibary \& Anouassi 1997; Tibary \& Vaughan 2006),

\section{Semen characteristics}

Specially designed artificial vaginas allow reliable collection of ejaculates (Lichtenwalner et al. 1996; Tibary \& Vaughan 2006), unfortunately a large number of ejaculates do not contain spermatozoa (Flores et al. 2002; Deen et al. 2003). 
Table 2: Effect of copulation length on ovulation and embryo recovery in dromedary camels (Tibary \& Anouassi 1997)

\begin{tabular}{lccc}
\hline Mating duration (minutes) & Number of females & $\begin{array}{c}\% \text { non-ovulating } \\
\text { females }\end{array}$ & $\begin{array}{c}\% \text { females with at } \\
\text { least one embryo }\end{array}$ \\
\hline Less than 1.5 minutes & 45 & 35.6 & 44.9 \\
1.5 to 3 & 232 & 13.8 & 53.5 \\
4 & 102 & 13.9 & 56.8 \\
$4.5-5$ & 102 & 16.7 & 65.9 \\
$5.5-6$ & 57 & 14 & 77.6 \\
$>6$ & 94 & 8.5 & 55.3 \\
\hline
\end{tabular}

Camelid semen has high viscosity, low sperm concentration and poor motility (Garnica et al. 1993; Tibary \& Anouassi 1997). Viscosity is attributed to mucopolysaccharides secreted from the bulbourethral glands or the prostate (Garnica et al. 1993). Liquefaction of camelid semen may take several hours and may be enhanced by exposure to hydrolytic and proteolytic enzymes (trypsin, collagenase, fibrolysin, hyalurodinase). A trypsin solution of 1:250 seems to be effective with minimal negative effects on spermatozoa (Bravo et al. 2000a).

The effects of the various sperm abnormalities on fertility have not yet been determined. Incidence of sperm abnormalities in the ejaculates is highly variable (Lichtenwalner et al. 1996; Flores et al. 2002; Urquieta et al. 2005). The incidence of cytoplasmic droplets is relatively high. The incidence of abnormalities is not affected by rank of ejaculate (Bravo et al. 1997). Concentration of the ejaculate remains stable if a period of at least 12 hours is allowed between successive ejaculations (Bravo et al. 1997; Urquieta et al. 2005). Male camelids may differ in their ability to induce ovulation (Tibary \& Anouassi 1997).

\section{Reproduction in the female camelid}

Reproductive parameters in the female (Table 3) present striking differences compared to ruminants. There are several distinct anatomical differences in the genital organs compared to the ruminant (i.e. large ovarian bursa, absence of intercornual ligaments, a well-developed papillae of the utero-tubal junction, arrangement of the cervical rings) (Fig. 1) (Tibary \& Anouassi 1997; Vaughan \& Tibary 2006).

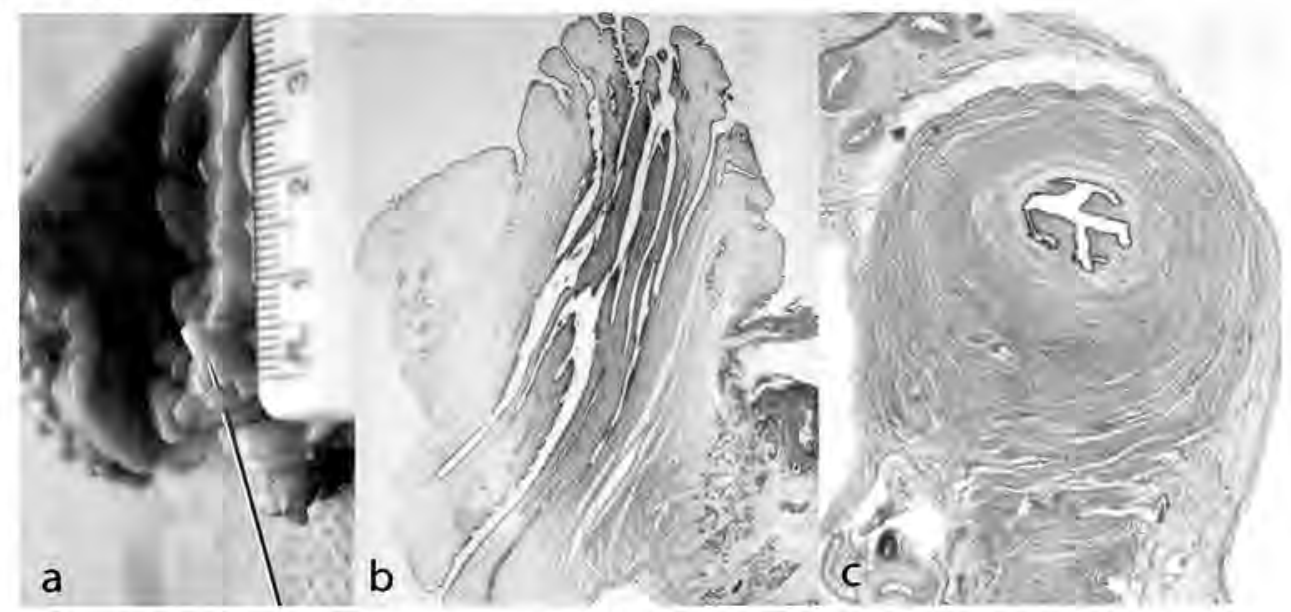

Fig. 1 Gross (a) and microanatomy (b and c) of the papillae of the utero-tubal junction in camelidae. Note the projection into the uterine lumen $(2$ to $5 \mathrm{~mm}$ ) and the strong smooth muscle sphincter. The utero-tubal junction serves as a sperm reservoir and selective passage of healthy embryos into the uterus 
Table 3: Reproductive parameters in female camelids (adapted from Tibary \& Anouassi 1997; Bravo 2002; Vaughan \& Tibary 2006,)

\begin{tabular}{|c|c|c|c|c|}
\hline Parameter & C. dromedarius & C. bactrianus & L.pacos & L. glama \\
\hline Puberty (months) & $24-48$ & $18-24$ & $4-6$ & $6-8$ \\
\hline Age at first breeding (months) & $36-48$ & $24-36$ & $12-18$ & $15-18$ \\
\hline \multicolumn{5}{|l|}{ Follicular wave phases duration (days) } \\
\hline Growth (days) & $10.5 \pm 0.5$ & $10.9 \pm 3$ & $3-9$ & $3-9$ \\
\hline Maturation & $7.6 \pm 0.8$ & $7 \pm 4.2$ & $2-8$ & $2-8$ \\
\hline Regression & $11.9 \pm 0.8$ & $11.9 \pm 4.2$ & $3-8$ & $3-8$ \\
\hline \multicolumn{5}{|l|}{ Ovulatory follicle characteristic } \\
\hline Minimum size (mm) & 9 & 9 & 7 & 8 \\
\hline Growth rate/day (mm) & 1.8 & 1.8 & 0.43 & $0.5-0.9$ \\
\hline Average size $(\mathrm{mm})$ & $10-18$ & $10-18$ & $8-10$ & $9-12$ \\
\hline Máximum size(mm) & 25 & 22 & 12 & 13 \\
\hline Incidence of anovulatory follicles $(\%$ & (\%) $40-50$ & ? & 5 & $10-40$ \\
\hline Anovulatory follicle regression (days & ys) $\quad 8-45$ & $?$ & $?$ & $4-22$ \\
\hline \multicolumn{5}{|l|}{ Corpus luteum characteristics } \\
\hline Size $(\mathrm{mm})$ & $15-25$ & $15-25$ & $11-15$ & $11-18$ \\
\hline Day at $\mathrm{CL}$ maximum size & $7+2 \pm 1,7$ & 7.3 & $7-8$ & 8 \\
\hline Luteolysis day & $10 \pm 1.2$ & 10.5 & $10-12$ & $10-12$ \\
\hline \multicolumn{5}{|l|}{ Pregnancy and Parfurition } \\
\hline Implantation (days) & 14 & 14 & $12-14$ & $12-14$ \\
\hline \multicolumn{5}{|l|}{ Average and range of pregnancy } \\
\hline length (days) & $\begin{array}{c}384 \\
(330-396)\end{array}$ & $\begin{array}{c}402 \\
(374-419)\end{array}$ & $\begin{array}{c}344 \\
(330-376)\end{array}$ & $\begin{array}{c}345 \\
(333-382)\end{array}$ \\
\hline Expulsion of fetus (minutes) & $\begin{array}{c}10.5+4.7 \\
(5-45)\end{array}$ & $\frac{26.8 \pm 12}{(5-45)}$ & $10-15$ & $10-15$ \\
\hline Delivery of placenta (minutes) & $\begin{array}{l}65 \pm 4.2 \\
(30-180)\end{array}$ & $69 \pm 47$ & $\begin{array}{c}88 \\
(40-143)\end{array}$ & $\begin{array}{c}77 \\
(45-240)\end{array}$ \\
\hline \multicolumn{5}{|l|}{ Postpartum } \\
\hline Utèrine involution (days) & $20-45$ & $?$ & 20 & 17 \\
\hline Postpartum ovarian activity (days) & $14-300^{*}$ & $?$ & 7 & 5 \\
\hline
\end{tabular}

*Extreme variation in onset of postpartum ovarian follicular activity is primarily due to nutritional condition and effect of lactation anoestrus and seasonality

\section{Puberty}

Puberty is generally defined in the female as the age at which ovulation and fertilization are possible. Endocrinological and clinical studies show that recruitment, growth and ovulation of follicles are possible in female NWC as early as 4 months of age. However early breeding may result in poor fertility due to ovulation failure and increased early pregnancy loss. Females are bred when they reach $60 \%$ of the adult weight (Vaughan \& Tibary 2006).

In OWC, normal follicular dynamics is present at 8 to 12 months of age in some breeds and under intensive management. However in nomadic conditions sexual activity does not start until 2 or 3 years of age. Nutritional status, season of birth, and breed of camel can affect the age at onset of puberty, age at first conception, and consequently the age at first parturition (Tibary et al. 2005b).

Seasonality of reproduction in the female

Seasonal pattern of reproduction in the female camelid is probably largely due to nutritional conditions (OWC and wild NWC) and management (NWC) (Tibary \& Anouassi 1997; Sghiri \& 
Driancourt 1999; Tibary et al. 2005b). The breeding season coincided with warmer months when ample forage is available. However, the relationship between nutrition and reproduction has not been thoroughly studied in camelids. In the dromedary, body condition score and particularly hump fat content was shown to have a direct effect on ovarian activity (Tibary \& Anouassi 1997). Also, leptinemia is positively related to hump fat content and is correlated to water and food deprivation. Recent studies show that this species has much higher hepatic lipogenic enzymes activity, an expression of leptin and leptin receptors, than in other ruminants. This suggests that leptin may be an important regulator of reproduction in this species (Bartha et al. 2005; Chillar et al. 2005a; 2005b; Sayed-Ahmed et al. 2005).

\section{Ovarian follicular activity}

In the absence of mating, there is a succession of overlapping follicular waves with highly variable rhythm showing 3 phases: growth, maturation and regression (Fig. 2) [(dromedary; (Skidmore et al. 1996a; Tibary \& Anouassi 1996); Ilamas (Chaves et al. 2002), alpacas (Vaughan et al. 2004) and vícunas (Miragaya et al, 2004)]. Follicular wave patterns are orchestrated by endocrinological events involving both hypothaloamo-pituitary-gonadal axis and local (inhibin) regulation (Vaughan \& Tibary 2006). Little is known about the mechanisms of recruitment of each follicular wave but these may involve FSH.

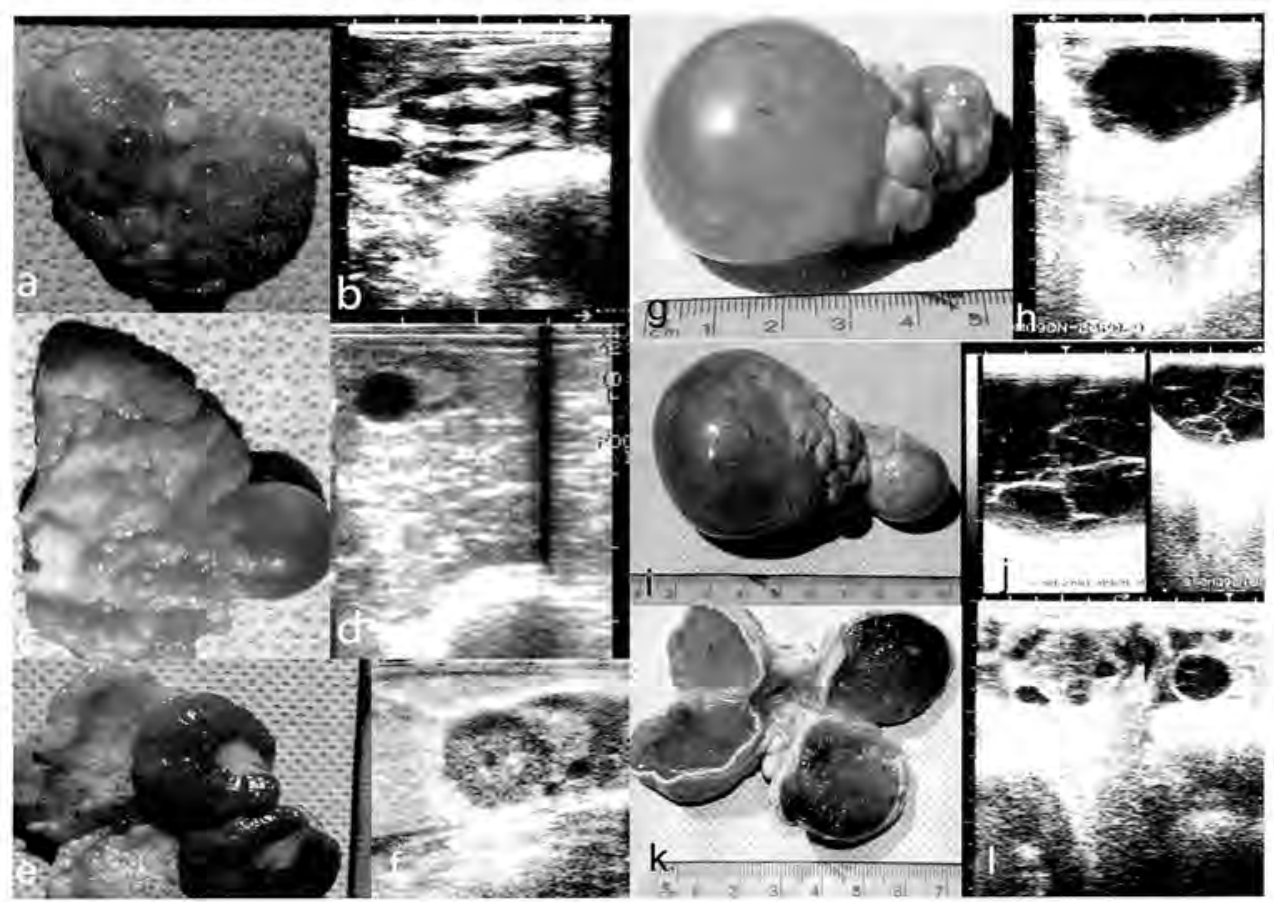

Fig. 2 Gross and ultrasonographic appearance of ovarian structures in camelids. Emergence of a new follicular wave growth $(a, b)$, dominant follicle $(c, d)$, mature corpora lutea $(e, f)$, anovulatory follicle $(g, h)$, anovulatory hemorrhagic follicle $(i, j)$ luteinized hemorrhagic follicles $(k, l)$

Follicle size is correlated with plasma 17 ß-oestradiol (oestradiol), oestrone sulphate and urinary oestrone sulphate in alpacas (Aba et al. 1995), llamas (Aba et al. 1995; Chaves et al. 2002) and 
dromedaries (Skidmore et al. 1996a; Tibary \& Anouassi 1997). Peak plasma oestradiol concentrations coincide with maximum follicle size (Chaves et al. 2002). Mature follicles may develop into large anovulatory follicles (Fig. 2). These regress slowly but do not seem to affect follicular growth. Some may become luteinized (Tibary \& Anouassi 1996).

\section{Ovulation}

Camelids are induced ovulators. An LH surge is observed within 15 to 40 minutes after mating and ovulation occurs in most females within 24 to 48 hours after mating (Marie \& Anouassi 1987; Bravo et al. 1992; Aba et al. 1995). Incidence of ovulation following mating varies from 60 to $100 \%$, occurring equally in the left and right ovaries (Tibary \& Anouasși 1996; Vaughan \& Tibary 2006).

\section{Mechanism of induction of ovulation}

Ovulation is induced by intramuscular injection of seminal plasma. The presence of an ovulation-induction factor (OIF) in semen was demonstrated in the bactrian camel (Zhao et al, 2001) and NWC recently (Adams et al. 2005). Absorption of the OIF seems to be dependant on hyperemia and endometrial irritation caused by copulation (Ratto et al. 2005b).

\section{Natural multiple ovulations}

Multiple ovulations (double and even triple) occur in 5 to $20 \%$ of natural matings (Tibary \& Anouassi 1996; Vaughan \& Tibary 2006). However, twin pregnancies and twin births are extremely rare.

\section{Spontaneous ovulations in camelidae}

Spontaneous ovulations have been reported, particularly in the postpartum female. Their incidence range from $3.5 \%$ to $40 \%$ (Nagy et al. 2005; Vaughan \& Tibary 2006). Some of these spontaneous ovulations could simply be luteinization of anovulatory follicles.

\section{Corpus luteum (CL) and lutyeolysis}

The luteal phase is short (Marie \& Anouassi 1987; Aba et al. 1995). The CL reaches its maximum size by 7 days post-breeding and luteolysis is initiated 9 to 10 days post-mating through prostaglandin $\mathrm{F}_{2 \alpha}\left(\mathrm{PGF}_{2 \alpha}\right.$ ) release (Aba et al. 1995; Skidmore et al. 1998). The role of oxytocin in luteal regression in camelids is unknown. There seems to be a difference in the luteolytic effects of the right vs. left uterine horn. Luteolytic activity of the right uterine horn is local while the left uterine horn has both a local and a systemic effect (Fernandez Baca et al. 1979). It is postulated that the left horn may induce luteolysis of a corpus luteum in the right ovary via a local veno-arterial pathway (Ghazi 1981; Del Campo et al. 1996).

\section{Pregnancy}

Fertilization and early embryo development

Fertilization rate is very high and embryo development is rapid. Embryos enter the uterine 
cavity approximately 5-6 days after ovulation at the hatching or early hatched blastocyst stage (McKinnon et al. 1994; Tibary \& Anouassi 1997; Tibary 2001b; Tibary 2001c). The embryo starts to elongate by Day 10 and the trophoblast establishes close contact with the endometrium by day 14 (Fig. 3) (Tibary 2001b).

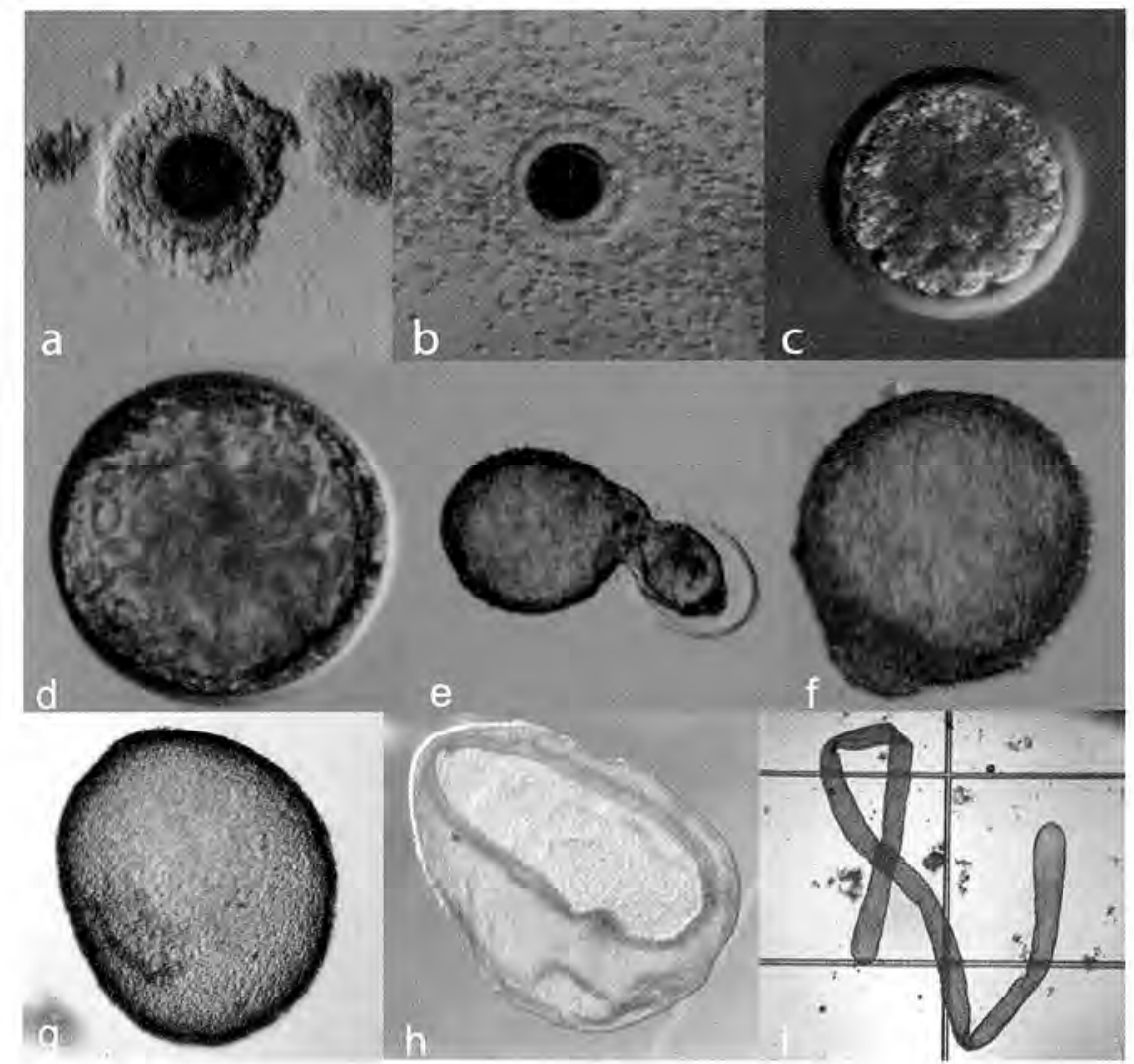

Fig. 3 Early embryo development in camelids. a) immature compact cumulus-oocytecomplex, b) expanded cumulus after maturation, c) day 5 morula $(260 \mu \mathrm{m})$, d) day 6.5 blastocyst ( $380 \mu \mathrm{m})$, e) day 7 hatching blastocysts; f) day 7.5 hatched blastoyst, g) day 8.5 collapsing blastocyst $(5 \mathrm{~mm})$; h) day 9.5 embryo $(9 \mathrm{~mm})$, i) day 13 elongating trophoblast $(5.5 \mathrm{~cm})$

\section{Maternal recognition and embryo migration}

The majority ( $98 \%$ ) of pregnancies occur in the left uterine horn regardless of the side of ovulation. Differential luteolysis occurs in the left and right uterine horns and may explain embryo migration from the right to the left uterine horn (Tibary \& Anouassi 1997; Vaughan \& Tibary 2006).

Embryonic signals have not been thoroughly investigated but they must be present before Day 9 after mating in order to rescue the corpus luteum of pregnancy (Aba et al. 1997). In the dromedary, the early embryo (Day 10) exhibits high aromatizing activity and synthesizes large amounts of estrogens. This coincides with the time of luteolysis and may be the first signal for maternal recognition and prevention of luteolysis. No interferon-like protein has yet been identified (Skidmore et al. 1994). High levels of oestrone sulphate are observed between Days 21 and 27 of pregnancy in alpacas and may be involved in maternal recognition of pregnancy (Vaughan \& Tibary 2006). 


\section{Placentation and fetal development}

The macro and microanatomy of the uteroplacental interface was recently described. Camelid placentation is eptheliochorial, diffuse microcotyledonary with the fetus completely covered by an epidermal membrane (Skidmore et al. 1996b; Tibary \& Anouassi 1997; Olivera et al. 2003a; Olivera et al. 2003b).

Implantation and placental development begins in the left horn around day 14 then extends to the right (Olivera et al. 2003a). Complete interdigitations between the membranes of uterine epithelial and trophoblastic cells are observed exclusively in the left horn in areas around the embryo. Specialized pre-contact zones, ectoplasmic pads, provide initial points of attachment and early metabolic maternal-fetal exchange (Abd-EInaeim et al. 2003). Aerolae are present at the gland regions and may play a role in nutrient transfer (Abd-Elnaeim et al. 2003; Olivera et al. 2003b). The contact surfaces of trophoblast and uterine epithelial cells show a richly glycosylated layer and many classes of glycan that may play a role in attachment, maternofetal interactions and embryo fixation at the implantation site (Jones et al. 2002; Olivera et al. 2003a).

Tropoblastic binucleated and multinucleated cells are present, but their function is not clear. There is no evidence of production of chorionic hormones (Jones et al. 2002; Olivera et al. 2003a).

\section{Endocrinology of pregnancy}

Ovulation, $\mathrm{CL}$ growth and progesterone production are similar in pregnant and non-pregnant camelids for the first 8 days after ovulation. A temporary decline in blood progesterone was reported from day 8 to 12 after mating during the period of maternal recognition of pregnancy (Aba et al. 1995). The CL is required to maintain pregnancy (Tibary \& Anouassi 1997; Vaughan \& Tibary 2006). Plasma progesterone concentration remains above $2 \mathrm{ng} / \mathrm{mL}$ but fluctuates throughout gestation then declines in the last 2 weeks of gestation (Tibary \& Anouassi 1997; Raggi et al. 1999).

Plasma oestradiol levels in pregnant camelids are generally low in early gestation, rise in mid-gestation, are very high in the last month of pregnancy then decline rapidly when the fetoplacental unit is disrupted at term (Aba et al. 1995; Tibary \& Anouassi 1997).

\section{Parturition}

Gestation length is highly variable and is affected by season (Davis et al. 1997; Tibary \& Anouassi 1997; Vaughan \& Tibary 2006). Parity of the dam and sex of the cria do not influence gestation length in NWC (Davis et al. 1997). However, these factors, as well as nutrition, are important in OWC (Tibary \& Anouassi 1997). Stages of parturition have been thoroughly described and are relatively short compared to ruminants (Table 3 ).

\section{Postpartum}

Uterine involution is rapid (Tibary \& Anouassi 1997; Bravo 2002). Gross anatomical involution is completed by 21 days postpartum. The interval from parturition to resumption of ovarian activity is 5 to 7 days in NWC. In NWC, mating and ovulation are possible by 10 days postpartum (Bravo et al. 1994). Conception rate returns to normal by 2 to 3 weeks postpartum, allowing production of one cria per year (Vaughan \& Tibary 2006). Lactational anoestrus is a problem in lactating camels particularly under desert conditions. Early weaning and nutritional supplementation allow early return to cyclicity and fertility (Tibary et al. 2005b). In the dromedary, early weaning ( 3 to 7 days of life) resulted in earlier onset postpartum ovarian activity (9.07 \pm 
7.77 days) and an average interval from calving to mating of $17.92 \pm 9.11$ days with a $76.8 \%$ pregnancy rate at the first postpartum mating (Khorchani et al. 2005). In addition, lactating fermales with good body condition at the time of calving were shown to have an earlier onset of postpartum ovarian activity and a shorter intercalving interval (i.e. 13 to 14 months instead of 22 to 24 months) (Sghiri 1988).

\section{Reproductive biotechnologies}

Semen preservation and artificial insemination

The use of artificial insemination (AI) has been reported in camelidae since the 60's (Tibary \& Anouassi 1997; Tibary 2001a). Most of the reported work is on Camelus bactrianus (Zhao et al. 1994).

\section{Semen preservation technology in camelids}

Short-term preservation of camelid semen has been attempted at different temperatures $\left(25^{\circ} \mathrm{C}\right.$, $30^{\circ} \mathrm{C}$ or $4^{\circ} \mathrm{C}$ ) using various extenders (Tibary 2001a). Complete liquefaction of semen before adding the extender poses some technical problems (Bravo et al. 2000b). Normal liquefaction of camelid semen may take several hours and may be enhanced by exposure to hydrolytic and proteolytic enzymes (trypsin, collagenase, fibrolysin, hyalurodinase). A trypsin solution of 1:250 seems to be effective with minimal negative effects on spermatozoa (Bravo et al. 2000a).

Semen has been frozen successfully for over 3 decades (Bravo et al. 2000b; Tibary 2001a). However, insemination trials were carried out mainly in the bactrian camel (Zhao et al. 1994). Llama and alpaca semen has been frozen using a variety of common ruminant techniques after liquefaction (Bravo et al. 2000b). Skim milk-egg-yolk ethylene glycol seems to result in higher motility and acrosome integrity (Santiani et al. 2005). Freezing and thawing procedures depend on the packaging method used (Bravo et al. 2000b; Tibary 2001a; Deen et al. 2003; Miragaya et al. 2006).

\section{Artificial insemination}

Insemination trials using cooled or frozen-thawed semen are scarce. Pregnancy rates following Al with fresh un-extended or extended semen are variable, Al is usually carried out 24 hours after induction of ovulation with hCG or GnRH. However, the overall pregnancy rate after Al is lower compared to natural service in most species except the bactrian camel (Tibary 2001a).

The method of insemination used in large camelids is similar to that used in the bovine (i.e. rectal-vaginal manipulation and use of either a cassou gun or an infusion pipette). In alpacas, insemination is performed by guiding an insemination pipette through a vaginoscope. A dose of $1 \mathrm{ml}$ of semen containing $400 \times 10^{6}$ spermatozoa seem to be adequate to guarantee ovulation and fertilization in the bactrian camel (Zhao et al. 1994). This dose can be reduced if ovulation is induced by hormonal treatment and the timing of insemination is determined with precision. In alpacas, conception was achieved following Al of $8 \times 10^{6}$ sperm cells (Bravo et al. 2000b). In our laboratory, deposition of $15 \times 10^{6}$ motile sperm cells, deep into the uterine horn ipsilateral to the side of ovulation 24 hours after administration of buserelin ( $25 \mathrm{ig}$ ), resulted in a $77.8 \%$ conception rate in ovulating females $(n=18)$ (A. Anouassi unpublished data).

Conception rates following artificial insemination with frozen semen vary between 50 and $80 \%$ in bactrian camels. On the other hand, conception rate achieved with frozen-thawed 
dromedary semen exhibiting very good post-thaw motility has been disappointing ( 10 to $15 \%$ ). There are few reports on Al with frozen-thawed NWC semen (Bravo et al. 2000b; Tibary 2001a; Miragaya et al. 2006)

\section{Interspecies artificial insemination trials}

Cross species insemination has long been performed in South America (Tibary 2001a). Studies using vicuna semen and paco-vicuna semen with female alpacas and llamas have yielded variable results. Trials to cross the guanaco with the dromedary camel have been reported resulting in the birth of three calves, however these pregnancies register a high rate of early loss (Skidmore et al. 2000). Cross-breeding between species of the same genus (i.e. C. bactrianus $\times C$. dromedaries, L. pacos $\times$ L. glama, L. guanacoe $\times$ L. glama) are fertile. Offspring resulting from $C$. dromedaries and $L$. guanacoe do not seem to be fertile.

\section{Multiple Ovulation and Embryo Transfer (MOET)}

MOET procedures for camelids are similar to those used for ruminants (McKinnon et al. 1994; Tibary \& Anouassi 1997; Tibary 2001c; Skidmore et al. 2002; Miragaya et al. 2006).

\section{Donor management}

Donors are superovulated using ovine (oFSH), porcine ( $\mathrm{pFSH}$ ), camel ( $\mathrm{CFSH})$, eCG or a combination of FSH and eCG. Treatment is initiated after synchronization of a follicular wave with progesterone, elimination of the dominant follicle by GnRH or hCG treatment, or at the early stage of the follicular wave (no follicle $>2 \mathrm{~mm}$ ). Optimal dose and frequencies of gonadotropin treatments vary from species to species (McKinnon et al. 1994; Tibary \& Anouassi 1997; Tibary 2001c; Miragaya et al. 2006). Development of mature follicles takes 6 to 8 days after initiation of gonadotropin treatment. Dromedary females seem to become refractory to eCG and oFSH or $\mathrm{pFSH}$ following multiple treatments. Superovulation problems are of two types: lack of response $(20 \%)$ or overstimulation (15 to $20 \%$ ) (Tibary \& Anouassi 1997). Embryo collection can also be performed without superovulation resulting in up to 29 pregnancies per female per season (A. Anouassi \& A. Tibary unpublished data).

Preliminary experiments on immunization of dromedaries and alpacas against a synthetic peptide fragment of a-inhibin are very encouraging. An increased number of ovulations ( 4 to 10) was observed in $60 \%$ of the immunized females (Tibary \& Anouassi 1997).

A single mating or insemination of donors is sufficient once follicles reach mature size. Donors are usually treated with hCG or GnRH agonist after mating in order to maximize ovulation rate.

\section{Embryo collection}

Non-surgical collection of embryos is done in the same manner described for cattle. Low epidu$\mathrm{ral}$ anesthesia is recommended in llamas and alpacas and in young dromedaries because of the smallness of the pelvis (Tibary 2001c).

Camelid embryos enter the uterus 6 to 6.5 days after ovulation. For maximum embryo recovery, flushing should be performed 7 to 8 days after ovulation. Embryo recovery rates (embryos recovered/ovulations) are highly variable and depends on many factors including superovulation treatment, fertility, management, collection date and technician experience (McKinnon et al. 1994; Tibary \& Anouassi 1997; Tibary 2001c). Reported recovery rates in non-superovulated llamas range from 52 to $61 \%$. Our recovery rate from the dromedary is $85 \%$ in single ovulators and $165 \%$ in double ovulators (Tibary \& Anouassi 1996). Only hatched blastocysts are transferable (Tibary 2001c). 
Management of recipients

Our results on over 6000 transfers show that recipients should ovulate one or two days after the donor. Synchronization of follicular development in donors and recipients has been attempted using progestagen with variable degrees of success (Tibary 2001c; Miragaya et al. 2006). We select females on the basis of follicular size from a large pool of recipients and induce ovulation with GnRH or hCG (Tibary \& Anouassi 1997). Some recipients lose their primary $\mathrm{CL}_{\text {, }}$ however, induction of new accessory corpora lutea by treating recipients with eCG/hCG during the first 2 months of pregnancy may be an approach for such recipients (Tibary 2001c).

Transfer of embryos into oestradiol/progesterone-treated, bilaterally ovariectomized recipient resulted in a $30 \%$ pregnancy rate. However, daily progesterone treatment is thereafter required throughout pregnancy. Spontaneous parturition has been reported in dromedary females receiving exogenous progesterone but this is not always the case. Moreover, progesterone treatment seems to increase the risk of dystocia, incomplete dilation of the cervix, premature placental separation and inadequate milk production.

\section{Pregnancy results with fresh embryos}

Embryos are generally transferred non-surgically in OWC, llamas and large alpacas. Whilst surgical transfer may be indicated in alpacas and vicunas, laparoscopy has been used in our laboratory for transfer of embryos in alpacas (Tibary 2001c).

Factors affecting pregnancy rates have been extensively studied in the dromedary (McKinnon et al. 1994; Tibary \& Anouassi 1997; Skidmore et al. 2002). Pregnancy rates are affected by season, quality of recipients and synchronization between donors and recipients. However, factors such as side of transfer, method of transfer, and age of the embryo do not have any effect on pregnancy rates. In our laboratory, MOET has been practiced on a commercial basis since 1992. During the period between 1992 and 1998, a total of 2653 fresh embryos were transferred, resulting in an overall pregnancy rate of $62 \%$. Pregnancy rates improved steadily from $30 \%$ to $70 \%$ over that period. It is not uncommon to achieve a pregnancy rate of $100 \%$ with some batches of embryos. Low pregnancy rates and high early pregnancy loss rates are observed when transfers are performed during the hottest months of the year (McKinnon et al. 1994; Tibary \& Anouasși 1997).

Alpaca embryos have been successfully transferred into llama recipients, resulting in normal births. Transfer of vicuna embryos into llamas or alpacas could be a good technique for the multiplication of this wild species (Miragaya et al. 2006).

\section{Cryopreservation of camelid embryos}

Freezing camelid embryos according to the protocols that are in widespread use for cryopreservation of ruminant embryos results in poor (0 to $15 \%$ ) pregnancy rates (McKinnon et al. 1994; Tibary \& Anouassi 1997), probably due to the stage of development at which they are collected (i.e hatched blastocyst) and to their size (i.e. 400 to 2500 microns). More recently the use of vitrification techniques resulted in higher pregnancy rates in Ilamas and dromedaries (Aller et al. 2002; Nowshari et al. 2005; Skidmore et al. 2005).

In vitro production of embryo

Oocyte collection

Ovarian slicing or follicular aspiration have both been used as sources of oocytes in Ilamas (Del Campo et al. 1995) and camels (Khatir et al. 2004; Nili et al. 2004; Kafi et al. 2005; Nowshari 
2005). In Ilamas, follicular aspiration results in a $62 \%$ recovery rate (i.e. number of oocytes complexes per aspirated follicle) with an average of 6 oocytes per female. Mincing produces higher yields of oocytes (27 per female) but a lower maturation rate (Del Campo et al. 1995). In dromedaries, recovery rates range from 31 to $49 \%$ following aspiration (Khatir et al. 2004) and $94 \%$ after follicle dissection (94\%) (Nowshari 2005). Cumulus-oocyte-complexes (COCs) are embedded in a large sheet of granulosa cells and are difficult to retrieve without direct visualization (Nowshari 2005). In dromedaries, more oocytes are recovered during the breeding season and in the absence of a corpus luteum (Tibary et al. 2005a).

Oocyte recovery rates of up to $80 \%$ have been reported in alpacas and vicunas using laparotomy. Laparoscopic ovum pickup results in slightly lower recovery rate but is safer. Recovery rates range from 75 to $85 \%$ after FSH/eCG stimulation (Tibary ét al. 2005a; Miragaya et al. 2006).

Transvaginal ultrasound-guided aspiration has been used in NWC and camels with collection rates ranging from 30 to $75 \%$ (Ratto et al. 2005a; Tibary et al. 2005a). Gonadotropin stimulation does not improve recovery rates but increases the number of oocytes obtained per female (Ratto et al. 2005a; Tibary et al. 2005a). Ovarian stimulation with eCG or FSH provides a uniform population of oocytes and offers a means to collect in vivo (cumulus expanded) matured COCs.

\section{In vitro oocyte maturation (IVM)}

Camelid oocytes can be matured in vitro in conditions similar to those described for ruminants (Tibary et al. 2005a). Camelid oocytes display a dark cytoplasm, due to presence of lipid particles, which makes evaluation very difficult. The perivitelline space (PVS) increases as the maturation process progresses until $24 \mathrm{~h}$ to a size which is maintained until $36 \mathrm{~h}$ of culture. A large number of microvilli are observed in the PVS in Metaphase II oocytes. Cortical granules migrate towards the peripheral areas of the ooplasm and form a lining in the suboolemmal area (Kafi et al. 2005).

In llamas, the optimal maturation rate $(62 \%)$ of oocytes is obtained after incubation for 32 to $36 \mathrm{~h}$ (Del Campo et al. 1995). Higher maturation rate $(80.6 \%)$ is obtained after $30 \mathrm{~h}$ incubation of oocytes aspirated after ovarian stimulation but oocyte quality and developmental ability may suffer (Ratto et al. 2005a). A 62\% maturation rate in a medium without added hormones was reported for oocytes collected $22 \mathrm{~h}$ after induction of an LH surge (Miráanal et al. 2006). In alpacas, the oocyte maturation rates are 40 to $46 \%$ for compact COCs collected 18 to $24 \mathrm{~h}$ after hCG administration to stimulated females and incubation of $26 \mathrm{~h}$. Similar results were obtained with vicuna oocytes (Miragaya et al. 2006).

In dromedaries, oocytes maturation rates vary from 50 to $83 \%$ after 30 to 36 hours of culture depending on conditions (Tibary et al. 2005a). Maturation rate of oocytes from non-stimulated animals are lower than those from stimulated animals $(63 \%$ vs. $83 \%)$. The addition of EGF and cysteamine to the maturation medium has a beneficial effect on nuclear and cytoplasmic maturation (Khatir et al. 2004; 2005). In the bactrian camel, $46.7 \%$ of oocytes achieved meiotic maturation after 24 to $26 \mathrm{~h}$ of culture. As with ruminant oocytes, maturation rate and development ability post-fertilization are dependant on follicular size (Tibary et al. 2005a).

\section{In vitro fertilization}

The first successful production of embryos by IVM/IVF was reported in Ilamas using epididymal sperm enriched by percoll gradient in presence of heparin $(2 \mathrm{or} 5 \mu \mathrm{g} / \mathrm{ml}$ ) (Del Campo et al. 1995). The oocyte penetration and development to the pronuleus stage rates were $29.2 \%$ and $57.1 \%$, respectively. Llama epididymal sperm was used to produce interspecies ( $L$. pacos $\times L$. glama) embryos. In vitro production of camel embryos was reported using fresh ejaculated 
(Khatir et al. 2004; Tibary et al. 2005a) and epididymal sperm (Nowshari 2005). Penetration $(68 \%)$ and cleavage rates $(40 \%)$ are promising with fresh ejaculated semen (Khatir et al. 2004; Khatir et al. 2005). The first dromedary offspring from transfer of IVP embryos using IVM/IVF was recently reported (Khatir \& Anouassi 2006).

\section{Intracytoplasmic sperm injection (ICSI)}

ICSI may be a valuable tool for production of interspecies embryos within the camelidae family. The only report of ICSI produced morulas was undertaken with Ilamas (Miragaya et al. 2006).

\section{Cloning}

Production of embryos by nuclear transfer using adult cells was reported in Ilamas. Fusion of the couplets was successful in $62.5 \%$ of attempts $(n=80)$ followed by cleavage rates of $32 \%$ to $40 \%$. Oviductal transfer of 8 - to 32-cell embryos and uterine transfer of a morula did not result in any pregnancy (Sansinena et al. 2003). Eight cells embryos were recently obtained by nuclear transfer in the dromedary after activation of oocytes with ionomycine followed by incubation in cyclohexidine (A. Anouassi unpublished data).

\section{Culture of IVP embryos}

In camels, we recently showed that embryos obtained by IVM/IVF and cultured to the hatched stage in semi-defined medium (mKSOMaa) have better in vivo development ability after transfer than those cultured with oviductal cells (Khatir et al. 2005). Factors affecting developmental ability of IVP embryos are currently being investigated.

\section{Conclusion}

Camelid reproductive biology offers interesting challenges to the scientist. Camelids are reputed to have poor reproductive performance, but in fact, these highly adapted species can maintain excellent reproductive performances even under harsh condition. Although our understanding of some of the reproductive phenomena has improved, there is still a need for research in areas that are critical for the management of individuals and herds. Breed differences within each species should be investigated. In males, spermatogenesis and sperm production studies are needed to elucidate the effect of season, ability to induce ovulation (OIF concentration) and interaction with some production characteristics (such as fiber, draught, etc.).

In the female, the mechanisms of luteolysis and maternal recognition of pregnancy remain unclear. This area is critical to understanding the causes of early pregnancy loss that typify IVP embryos and heat stressed animals. Studies using interspecific embryo transfer, interspecific embryo production by ICSI, or cross-species nuclear transfer would allow more genomic studies on reproductive phenomena.

Semen physiology and artificial insemination studies are limited by the lack of an easy and reliable method for semen collection, as well as the gelatinous nature of the semen. Data on use of frozen-thawed semen remains limited to the bactrian camel. Further studies on factors affecting oocyte maturation and activation, and developmental ability of IVP embryos are needed. Embryo transfer technology is well established and could be an excellent tool to study interspecies placentation. Interspecific pregnancies (alpaca in llama, bactrian in dromedary) have been obtained and resulted in births but no trials have been conducted between OWC and NWC (e.g. bactrian in camel, alpaca in camel, ect.). 
Finally, to improve herd performance it is necessary to study the interaction among season, nutrition and lactation with special attention to the role of leptin in regulation of reproductive activity and effect of metabolism on hormone levels.

\section{References}

Aba MA, Forsberg M, Kindahl H, Sumar J \& Edqvist LE 1995 Endocrine changes after mating in pregnant and non-pregnant llamas and alpacas. Acta Veterinaria Scandinavica 36 489-498.

Aba MA, Bravo PW, Forsberg M \& Kindahl H 1997 Endocrine changes during early-pregnancy in the alpaca. Animal Reproduction Science 47 273-279.

Abd-Elnaeim MMM, Saber A, Hassan A, Abou-Elmagd A, Klisch K, Jones CJP \& Leiser R 2003 Development of the areola in the early placenta of the onehumped camel (Camelus dromedarius): a light, scanning and transmission electron microscopical study. Anatomia Histologia Embryologia 32 326-334.

Adams GP, Ratto MH, Huanca W \& Singh J 2005 Ovulation-inducing factor in the seminal plasma of alpacas and Ilamas. Biology of Reproduction 73 452457.

Al-Qarawi AA, Abdel-Rahman HA, El-Belely MS \& ElMougy SA 2001 Intratesticular morphometric, cellular and endocrine changes around the pubertal period in dromedary camels. Veterinary Journal $\mathbf{1 6 2}$ 241-249.

Aller JF, Rebuffi GE, Cancino AK \& Alberio RH 2002 Successful transfer of vitrified llama (Lama glama) embryos. Animal Reproduction Science 73 121-127.

Anouassi A, Lahlou-Kassi A, Combarnous Y, Sghiri A \& Martinat N 1988 Performance and endocrine approach for reproductive management in the camel (Camelus dromedarius). Proceedings of FIS/SIDA Workshop on Camels. Addis-Ababa, Ethiopia.

Bartha T, Sayed-Ahmed A \& Rudas P 2005 Expression of leptin and its receptors in various tissues of ruminants. Domestic Animal Endocrinology 29 193-202

Bravo PW, Stabenfeldt GH, Fowler ME \& Lasley BL. 1992 Pituitary response to repeated copulation and/ or gonadotropin-releasing hormone administration in Ilamas and alpacas. Biology of Reproduction 47 884-888.

Bravo PW, Fowler ME \& Lasley BL 1994 The postpartum llama: fertility after parturition. Biology of Reproduction 51 1084-1087.

Bravo PW, Flores D \& Ordonez C 1997 Effect of repeated collection on semen characteristics of alpacas. Biology of Reproduction 57 520-524.

Bravo PW, Ccallo M \& Garnica J 2000a The effect of enzymes on semen viscosity in Llamas and Alpacas. Small Ruminant Research 38 91-95.

Bravo PW, Skidmore JA \& Zhao XX 2000b Reproductive aspects and storage of semen in Camelidae. Animal Reproduction Science 62 173-193

Bravo PW (2002) The reproductive process of South American camelid. Printed by Seagull Printing, Salt
Lake City, IT, USA

Bustos-Obregon E, Rodriguez A \& Urquieta B 1997 Spermatogenic cycle stages in the seminiferous epithelium of the vicuna (Vicugna vicugna). In Recent advances in microscopy of cells, tissue and organs, Motta P.M. ed Delfino Editor, Roma, Italy 579-584. 1997.

Chaves MG, Aba M, Aguero A, Egey J, Berestin V \& Rutter B 2002 Ovarian follicular wave pattern and the effect of exogenous progesterone on follicular activity in non-mated llamas. Animal Reproduction Science $6937-46$

Chillard Y, Bengoumi M, Delavaud C, Faulconnier $\mathbf{Y}$ \& Faye B 2005a Body lipids and adaptation of camel to foot and water shorfage: New data on adipocyte size and plasma leptin. In: Desertification combat and food safety; The added value of camel producers, Faye B and Esenov P (ed) NBato Science Series. I, Vo 362, Pages 135-145

Chilliard Y, Delavaud C \& Bonnet M 2005b. Leptin expression in ruminants: Nutritional and physiological regulations in relation with energy metabolism. Domestic Animal Endocrinology $293-22$

Davis GH, Dodds KG, Moore GH \& Bruce GD 1997 Seasonal effects on gestation length and birth-weight in alpacas. Animal Reproduction Science $46297-$ 303

Deen A, Vyas S \& Sahani MS 2003 Semen collection. cryopreservation and artificial insemination in the dromedary camel. Animal Reproduction Science 77 223-233

Del Campo MR, Del Campo $\mathrm{CH}$, Adams GP \& Mapletoft RJ 1995 The application of new reproductive technologies to South American camelids. Theriogenology $\mathbf{4 3}$ 21-30

Del Campo MR, Del Campo CH \& Ginther Of 1996 Vascular provisions for a local utero-ovarian crossover pathway in New World camelids. Theriogenology 46 983-991

Delhon GA \& von Lawzewitsch I 1987 Reproduction in the male llama (Lama glama), a South American camelid I. Spermatogenesis and organizations of the intertubular space of the mature testis. Acta Anatomia $12959-66$

Delhon G \& Von Lawzewitsch I 1994 Ductus epididymidis compartments and morphology of epididymal spermatozoa in llamas. Anatomia Histologia Embryologia 23 217-225

Fernandez Baca S, Hansel W, Saatman R, Sumar J \& Novoa C 1979 Differential luteolytic effects of right and left uterine horns in the alpaca. Biology of Reproduction 20 586-595 
Flores P, Garcia-Huidobro J, Munoz C, Bustos-Obregon E \& Urquieta B 2002 Alpaca semen characteristics previous to a mating period. Animal Reproduction Science 72 259-266

Garnica J, Achata R \& Bravo PW (1993) Physical and biochemical characteristics of alpaca semen. Animal Reproduction Science 32 85-90

Ghazi R 1981 Angioarchitectural studies of the uteroovarian component in the camel (Camelus dromedarius). Journal of Reproduction and Fertility 61 43-46.

Jones CJP, Abd-EInaeim M, Bevilacqua E, Oliveira LV \& Leiser R 2002 Comparison of uteroplacental glycosylation in the camel (Camelus dromedarius) and alpaca (Lama pacos). Reproduction 123 115-126

Kafi M, Mesbah F, Nili H \& Khalili A 2005 ChronologiCal and ultrastructural changes in camel (Camelus dromedarius) oocytes during in vitro maturation. Theriogenology 63 2458-2470

Khatir H, Anouassi A \& Tibary A 2004 Production of dromedary (Camelus dromedarius) embryos by IVM and IVF and co-culture with oviductal or granulosa cells. Theriogenology 62 1175-1185

Khatir H, Anouassi A \& Tibary A 2005 In vitro and in vivo developmental competence of dromedary (Camelus dromedarius) embryos produced in vitro using two culture systems (mKSOMaa and oviductal cells). Reproduction in Domestic Animals 40245 249

Khatir H \& Anouassi A 2006 The first dromedary (Camelus dromedarius) offspring obtained from in vitro matured, in vitro fertilized and in vitro cultured abattoir-derived oocytes. Theriogenology 65 $17127-1736$

Khorchani T, Hammadi M \& Moslani M 2005 Artificial nursing of camel calves: An effective technique for calves safeguard and improving herd productivity. In: Desertification combat and food safety; The added value of camel producers, Faye B and Esenov P (ed) NBato Science Series 1, Vo 362, Pages 168-172

Lichtenwalner AB, Woods GL \& Weber JA 1996 Seminal collection, seminal characteristics and pattern of ejaculation in Ilamas. Theriogenology 46 293-305

Lichtenwalner AB, Woods GL \& Weber JA 1997 Pattern of emission during copulation in male llamas. Biology of Reproduction 56 298-298

Marie M \& Anouassi A 1987 Induction of Juteal activity and progesterone secretion in the nonpregnant onehumped camel (Camelus dromedarius). Journal of Reproduction and Fertility 80 183-192

McKinnon AO, Tinson AH \& Nation G 1994 Embryo transfer in dromedary camels. Theriogenology $\mathbf{4 1}$ $145-150$

Miragaya MH, Aba MA, Capdevielle EF, Ferrer MS, Chaves MG, Rutter B \& Aguero A 2004 Follicular activity and hormonal secretory profile in vicuna (Vicugna vicugna). Theriogenology 61 663-671

Miragaya MH, Chaves MG \& Agüero A 2006 Reproductive biotechnology in South American camelids. Small Ruminant Research 61 299-310

Nagy P, Jutka J \& Wernery U 2005 Incidence of spon- taneous ovulation and development of the corpus luteum in non-mated dromedary camels (Camelus dromedarius). Theriogenology 64 292-304

Nili H, Mesbah F, Kafi M \& Esfahani MHN 2004 Light and transmission electron microscopy of immature camelus dromedarius oocyte. Anatomia Histologia Embryologia 33 196-199.

Nowshari MA 2005 The effect of barvesting technique on efficiency of oocyte collection and different maturation media on the nuclear maturation of oocytes in camels (Camelus dromedarius). Theriogenology 63 2471-2481

Nowshari MA, Ali SA \& Saleem S 2005 Offspring re sulting from transfer of cryopreserved embryos in camel (Camelus dromedarius). Theriogenology 63 2513-2522.

Olivera L, Zago D, Leiser R, Jones C \& Bevilacqua E 2003a Placentation in the alpaca Lama pacos. Analomy and Embryology 207 45-62

Olivera LVM, Zago DA, Jones CJP \& Bevilacqua E 2003b Developmental changes at the materno-embryonic interface in early pregnancy of the alpaca, Lamos pacos. Anatomy and Embryology 207317 331.

Raggi LA, Ferrando G, Parraguez VH, MacNiven V \& Urquieta B 1999 Plasma progesterone in alpaca (Lama pacos) during pregnancy, parturition and early postpartum. Animal Reproduction Science 54 245-249

Ratto M, Berland M, Huanca W, Singh J \& Adams GP 2005 a In vitro and in vivo maturation of llama oocytes. Theriogenology 63 2445-2457

Ratto MH, Huanca W, Singh I \& Adams GP 2005b Local versus systemic effect of ovulation-inducing factor in the seminal plasma of alpacas, Reproductive Biology and Endocrinology 3 online paper 29.

Sansinena MJ, Taylor SA, Taylor PJ, Denniston RS \& Godke R 2003 Production of nuclear transfer llama (Lama glama) embryos from in vitro matured Ilama oocytes. Cloning and Stem Cells 5 191-198

Santiani A, Huanca W, Sapana R, Huanca T, Sepulveda N \& Sanchez R 2005 Effects on the quality of frozen-thawed alpaca (Lama pacos) semen using two different cryoprotectants and extenders. Asian Journal of Andrology 7 303-309

Sayed-Ahmed A, Rudas P \& Bartha T 2005 Partial cloning and localisation of leptin and its receptor in the one-humped camel (Camelus dromedarius). Veterinary Journal 170 (2) 264-267

Sghiri A 1988 Evaluation des performances de reproduction d'un troupeau camelin (Camelus dromedarius) à Laayoune. Thèse de Doctorat Vétérinaire, Institut Agronomique et vétérinaire Hassan II, Rabat, Morocco.

Sghiri A \& Driancourt MA 1999 Seasonal effects on fertility and ovarian follicular growth and maturation in camels (Camelus dromedarius). Animal Reproduction Science 55 223-237

Skidmore JA, Allen WR \& Heap RB 1994 Oestrogen synthesis by the peri-implantation conceptus of the one-humped camel (Camelus dromedarius). Journal Reproduction and Fertility 101 363-367 
Skidmore JA, Billah M \& Allen WR 1996a The ovarian follicular wave pattern and induction of ovulation in the mated and non-mated one-humped camel (Camelus dromedarius). Journal of Reproduction and Fertilility 106 185-192

Skidmore JA, Wooding FBP \& Allen WR 1996b Implantation and early placentation in the one-humped camel (Camelus dromedarius). Placenta 17 253-262

Skidmore JA, Starbuck GR, Lamming GE \& Allen WR 1998 Control of luteolysis in the one-humped camel (Camelus dromedarius). Journal of Reproduction and Fertility 114 201-209

Skidmore JA, Billah M, Allen WR \& Short RV 2000 Modern reproductive methods to hybridize old and new world camelids: Camelus dromedarius $x$ Lama guanicoe. Reproduction in Domestic Animals Suppl. 6 100-103

Skidmore JA, Billah M \& Allen WR 2002 Investigation of factors affecting pregnancy rate after embryo transfer in the dromedary camel. Reproduction, Fertility and Development 14 109-116

Skidmore JA, Billah M \& Loskutoff NM 2005 Comparison of two different methods for the vitrification of hatched blastocysts from the dromedary camel (Camelus dromedarius). Reproduction Fertility and Development 17 523-527

Tibary A \& Anouassi A (1996) Ultrasonographic changes of the reproductive-tract in the female camel (Camelus-Dromedarius) during the follicular cycle and pregnancy. lournal of Camel Practice and Research $371-90$

Tibary A \& Anouassi A 1997 Theriogenology in Camelidae: Anatomy, physiology, BSE, pathology and artificial breeding: Actes Editions, Institut Agronomique et Veterinaire Hassan II, 1997.

Tibary A 2001a Semen preservation in camelids. Proceedings of the Annual Conference of the Society for Theriogenology, September 12-15, 2001, Vancouver, BC, Canada, pp 369-378

Tibary A 2001b Fertilization, embryo and fetal development in camelids. Proceedings of the Annual Conference of the Society for Theriogenology, September 12-15, 2001, Vancouver, BC, Canada, pp 387396
Tibary A 2001c Embryo transfer in camelids. Proceedings of the Annual Conference of the Society for Theriogenology, September 12-15, 2001. Vancouver, BC, Canada, pp 379-386

Tibary A, Anouassi A \& Khatir H 2005a Update on reproductive biotechnologies in small ruminants and camelids. Theriogenology 64 618-638

Tibary A, Anouassi A \& Sghiri A 2005b Factors affecting reproductive performance of camels at the herd and individual level. In Desertification combat and food safety; The added value of camel producers, Faye B and Essenov P (ed) NBato Science Series I, Vo 362, Pages 97-114.

Tibary A \& Vaughan 12006 Reproductive physiology and infertility in male South American camelids: A review and clinical observations. Small Ruminant Research 61 283-298

Tingari MD \& Moniem KA 1979 On the regional histology and histochemistry of the epididymis of the camel (Camelus dromedarius). Journal of Reproduction and Fertility 57 11-20

Urquieta B, Cepeda R, Caceres JE, Raggi LA \& Rojas IR 1994 Seasonal variation in some reproductive parameters of male vicuna in the High Andes in northern Chile. Journal of Arid Environments 2679 87

Urquieta B, Flores P, Munoz C, Bustos-Obregon E \& Garcia-Huidobro J 2005 Alpaca semen characteristics under free and directed mounts during a mating period. Animal Reproduction Science 90 329-339

Vaughan J \& Tibary A 2006 Reproduction in female South American camelids: A review and clinical observations. Small Ruminant Research 61 259-281

Vaughan IL, Macmillan KL \& D'Occhio MJ 2004 Ovarian follicular wave characteristics in alpacas. Animal Reproduction Science 80 353-361

Zhao XX, Huang YM \& Chen BX 1994 Artificial insemination and pregnancy diagnosis in the Bactrian camel (Camelus bactrianus). Journal of Arid Environments 26 61-65

Zhao XX, Li XL \& Chen BX 2001 Isolation of ovulationinducing factors in the seminal plasma of bactrian camel (Camelus bactrianus) by DEAE-cellulose chromatography. Reproduction in Domestic Animals 36 177-181 